\title{
Dynamical contribution to sea surface salinity variations in the eastern Gulf of Guinea based on numerical modelling
}

\author{
Henrick Berger ${ }^{1,2,{ }^{*}, \text { Anne Marie Treguier }}{ }^{1}$, Nicolas Perenne $^{2}$, Claude Talandier $^{1}$
}

\author{
${ }^{1}$ Laboratoire de Physique des Oceans, CNRS-Ifremer-UBO-IRD, BP70, Plouzane, France \\ ${ }^{2}$ Actimar, 36 quai de la douane, Brest, France \\ *: Corresponding author : Henrick Berger, email address : $\underline{\text { henrick.berger@ifremer.fr }}$
}

\begin{abstract}
:
In this study, we analyse the seasonal variability of the sea surface salinity (SSS) for two coastal regions of the Gulf of Guinea from 1995 to 2006 using a high resolution model $\left(1 / 12^{\circ}\right)$ embedded in a Tropical Atlantic $\left(1 / 4^{\circ}\right)$ model. Compared with observations and climatologies, our model demonstrates a good capability to reproduce the seasonal and spatial variations of the SSS and mixed layer depth. Sensitivity experiments are carried out to assess the respective impacts of precipitations and river discharge on the spatial structure and seasonal variations of the SSS in the eastern part of the Gulf of Guinea. In the Bight of Biafra, both precipitations and river runoffs are necessary to observe permanent low SSS values but the river discharge has the strongest impact on the seasonal variations of the SSS. South of the equator, the Congo river discharge alone is sufficient to explain most of the SSS structure and its seasonal variability. However, mixed layer budgets for salinity reveal the necessity to take into account the horizontal and vertical dynamics to explain the seasonal evolution of the salinity in the mixed layer. Indeed evaporation, precipitations and runoffs represent a relatively small contribution to the budgets locally at intraseasonal to seasonal time scales. Horizontal advection always contribute to spread the low salinity coastal waters offshore and thus decrease the salinity in the eastern Gulf of Guinea. For the Bight of Biafra and the Congo plume region, the strong seasonal increase of the SSS observed from May/June to August/September, when the trade winds intensify, results from a decreasing offshore spread of freshwater associated with an intensification of the salt input from the subsurface. In the Congo plume region, the subsurface salt comes mainly from advection due to a strong upwelling but for the Bight of Biafra, entrainment and vertical mixing also play a role. The seasonal evolution of horizontal advection in the Bight of Biafra is mainly driven by eddy correlations between salinity and velocities, but it is not the case in the Congo plume.
\end{abstract}

Keywords: Gulf of Guinea ; Salinity ; Modelling ; Congo ; Bight of Biafra ; Mixed layer budget

* This paper is a contribution to the special issue on tropical Atlantic variability and coupled model climate biases that have been the focus of the recently completed Tropical Atlantic Climate Experiment (TACE), an international CLIVAR program (http://www.clivar.org/organization/atlantic/tace). This special issue is coordinated by William Johns, Peter Brandt, and Ping Chang, representatives of the TACE Observations and TACE Modeling and Synthesis working groups.

\section{Introduction}

The Gulf of Guinea is a region of importance for the development of the African Monsoon (Redelsperger et al. 2006) because of the ocean/atmosphere interactions. 
39

The existence of a shallow thermocline and mixed layer (de Boyer Montegut et al 2004) in the eastern part of the Tropical Atlantic, that can be easily eroded, is one of the reasons for the existence of the Atlantic cold tongue which is a key feature for the formation of the monsoon. Stratification is thus one of the elements which must be understood to better describe the fluxes and interactions between the tropical ocean and the atmospheric boundary layer. Already sharp because of the thin thermocline, the stratification in the central and eastern part of the Gulf of Guinea is reinforced by a strong halocline due to the presence of anomalously freshwaters extending from the eastern coast to $0^{\circ} \mathrm{E}$ or even farther west (Dessier and Donguy 1994), and a subsurface salinity maximum due to subtropical waters advected by the Equatorial undercurrent (Blanke et al 2002).

In the Bight of Biafra north of the Equator and offshore Angola and Gabon south of it, the low salinity values observed in the surface layer (lower than 31 psu in the north and $32 \mathrm{psu}$ in the south, Figure 1) result from high precipitations and river discharge. The importance of the salinity gap between these water masses and the tropical surface water (close to 35.5 psu, Stramma and Schott (1999)), can be easily explained by the amount of freshwater concerned. The Congo river is the second most important in the world with an average discharge of $40 \mathrm{mSv}$ (Mahé and Olivry 1999) and the Niger river is the twelfth with $7 \mathrm{mSv}$ (Dai and Trenberth 2002), both with large seasonal variations. Precipitations over the whole Gulf of Guinea are substantial (140 mSv using the dataset of Large and Yeager (2009)) and also vary seasonally.

A large number of studies has been devoted to the variability of temperature in the mixed layer of the tropical Atlantic (see Giordani et al (2013), Hummels et al (2012) or Jouanno et al (2011) for recent examples). However, in situ observations 
64

of salinity have a sparse spatial and temporal resolution compared with temperature (Reverdin et al 2007). Remote sensing of salinity has become possible very recently, with large uncertainties still (Tzortzi et al 2013). Da-Allada et al (2013a) recently computed a budget of mixed layer salinity from in situ observations in the whole tropical Atlantic. However, the sparseness of the data makes the results questionable for the coastal regions of the eastern Gulf of Guinea where the lowest salinity waters are found.

In this paper we attempt to better understand the mechanisms which drive the seasonal variations of the SSS of the eastern Gulf of Guinea, concentrating on the Bight of Biafra and the Congo plume regions. Our objectives are : 1) to determine the exact contribution of the precipitations and river outflow in term of mean state and seasonal variations of the SSS, 2) to determine the dynamical contributions to the seasonal cycle and especially the importance of horizontal and vertical processes.

As in-situ observations for the salinity in these regions are not sufficient to make a complete analysis of the seasonal variations of the SSS, we choose to use numerical modelling to assess the mechanisms corresponding to these two questions. Regarding the impact of freshwater sources, our analyses are based on sensitivity experiments on the freshwater forcing. We evaluate the key mechanisms based on the diagnostics introduced by Vialard et al (2001) for mixed layer temperature, but applied here to the seasonal mixed layer budget for salinity.

This paper is organized as follow. Section 2 describes the characteristics of our regional model. Section 3 presents a discussion about the impact of precipitations and river runoffs in term of spatial repartition of the SSS and mean amplitude of the seasonal variations. In section 4 we quantify the importance of various physical 
89

\section{Numerical model and validation}

2.1 Model characteristics

Because of sparse spatial and temporal resolution of in-situ data for SSS, a regional ocean model is set up in order to represent the oceanic processes in the Gulf of Guinea. We use the NEMO 3.2.1 numerical model (Madec 2008) with AGRIF online refinement to combine $1 / 4^{\circ}$ and $1 / 12^{\circ}$ grids with two ways interactions (Debreu and Blayo 2008). Our configuration is based on the $1 / 4^{\circ}$ global experiment ORCA025.L75 developed by the DRAKKAR team (Barnier et al 2006) and the regional $1 / 12^{\circ}$ configuration used by Guiavarc'h et al (2008). The domain covers the Tropical Atlantic (from $30^{\circ} \mathrm{S}$ to $30^{\circ} \mathrm{N}$ and from $60^{\circ} \mathrm{W}$ to $15^{\circ} \mathrm{E}$ ) with a $1 / 4^{\circ}$ grid and the Gulf of Guinea with a $1 / 12^{\circ}$ one (AGRIF zoom from $10^{\circ} \mathrm{W}$ to $15^{\circ} \mathrm{E}$ and from $15^{\circ} \mathrm{S}$ to $8^{\circ} \mathrm{N}$ ), these grids can be seen on Figure 1 . The $1 / 12^{\circ}$ resolution is chosen for the eastern Gulf of Guinea because currents on the continental slope are too weak compared with observations at $1 / 4^{\circ}$ (Guiavarc'h et al (2008), their Figure 7). Both grids have 75 vertical levels in partial steps with a first layer of 1 meter thickness. We use extractions of the global $1 / 4^{\circ}$ and $1 / 12^{\circ}$ bathymetries built by Mercator Ocean (http://www.mercator-ocean.fr). Radiative open boundaries (Treguier et al 2001) are set up in the eastern, southern and northern limits of the $1 / 4^{\circ}$ grid. They radiate perturbation outward and relax the model variables to 5 day averages of the ORCA025.L75 global experiment. 
An energy-enstrophy conserving momentum advection scheme (Penduff et al 2007) is used for the dynamics. Lateral diffusion of momentum is done with a horizontal bilaplacian operator with coefficient $1.5 \mathrm{e}^{11} \mathrm{~m}^{4} \cdot \mathrm{s}^{-2}$ in the $1 / 4^{\circ}$ grid and $1.2 \mathrm{e}^{10} \mathrm{~m}^{4} \cdot \mathrm{s}^{-2}$ in the $1 / 12^{\circ}$ grid. The time steps are $2400 \mathrm{~s}$ and $800 \mathrm{~s}$ for the $1 / 4^{\circ}$ and $1 / 12^{\circ}$ grids respectively. The advection of passive tracers is based on a Total Variance Dissipation (TVD) scheme and diffusion is parameterized by a laplacian isopycnal operator with coefficient $300 \mathrm{~m}^{2} \cdot \mathrm{s}^{-1}\left(1 / 4^{\circ}\right)$ and $100 \mathrm{~m}^{2} \cdot \mathrm{s}^{-1}\left(1 / 12^{\circ}\right)$. The vertical diffusion coefficient is similar for the two grids and is given by a Turbulent Kinetic Energy (TKE) second order closure scheme (Blanke and Delecluse 1993). An enhanced vertical diffusion of $1 \mathrm{~m}^{2} \cdot \mathrm{s}^{-1}$ is applied on tracer and momentum in case of static instability. The Agrif coupling between our grids uses a laplacian diffusivity in the sponge layer equal to $300 \mathrm{~m}^{2} \cdot \mathrm{s}^{-1}$ for tracers and dynamics. The baroclinic update between grids is done at each time step of the mother grid. The model starts from a climatology of temperature and salinity (Levitus 1986) in 1990 and is integrated to 2006. To perform all the diagnostics done in this paper, we use 5 day averages for the period from 1995 to 2006.

The atmospheric forcing at the surface is computed with the CORE bulk formulation (Large and Yeager 2004). We use a composite forcing based on the DFS4.3 forcing (Brodeau et al 2010) set up by the DRAKKAR team and the ERA-interim forcing from the ECMWF. From DFS4.3 we use observed precipitations and solar radiation (based on satellite observations from the dataset of Large and Yeager (2009); precipitations are based on the Global Precipitation Climatology Project, GPCP). From ERA-interim we use temperature, humidity and winds at 2 meters. The model takes into account the diurnal cycle on solar radiation. The short wave 
radiation penetration depends on the ocean colour based on a SeaWifs climatology, so the extinction coefficients vary horizontally (Madec 2008).

River runoffs are prescribed by a surface freshwater flux near the river mouth and along the coast. Coastal runoff values come from the inter-annual dataset of Dai et al (2009) based on in-situ measurements and model reconstructions with a River Transport Model (RTM) over the period 1990-2004. The focus of this study being the seasonal cycle, our reference experiment (hereafter REF) is run with climatological runoffs. Another experiment (D09) is run with inter-annually varying runoffs. The climatological runoff values for REF are the averaged fields of D09 from 1990 to 2004. Indeed, for the period considered here, the use of the Dai and Trenberth (2002) climatology implies an important overestimation of the river runoffs relative to the inter-annual dataset, because of a decreasing inflow in this region since 1948 (equal to $15 \%$ from Dai et al (2009) and Mahé and Olivry (1999)). The comparison of the spatially averaged SSS between the REF simulation and D09 (Figure 2a) shows that the inter-annual variations of the river runoffs do not impact much the SSS variability. Especially, the inter-annual SSS anomalies of these two experiments are practically equal (Figure 2b). Finally, as Ferry and Reverdin (2004) demonstrate that the only simulation they perform which is able to reproduce the inter-annual variability in the western Tropical Atlantic is the one with no SSS restoring, we do not use surface restoring for salinity to avoid excessive damping of the inter-annual variability. 


\subsubsection{Surface salinity}

Our model is comparable to those used by Peter et al (2006) and Jouanno et al (2011), and shares many of their characteristics concerning the heat content in the surface and subsurface layer. Here we focus the validation on the salinity field for our REF experiment; more details are found in Berger (2012). The comparison between the SSS of our REF experiment and the ARV09 climatology from Gaillard et al (2009) demonstrates the good capability of the model to reproduce the three main features of the SSS in the Gulf of Guinea (Figure 3). First, the southwestward salinity gradient at regional scale appears similar in the climatology and the model, the latter being less smooth because of its better spatial resolution. Second, the large plumes and desalinated waters in the Bight of Biafra (with the Niger and some important rivers) and offshore Gabon and Angola between 8 and $4^{\circ} \mathrm{S}$ (with the Congo River) appear positioned correctly. Finally, desalinated waters north and south of the equator are separated by higher salinity water offshore the Cap Lopez, near $1^{\circ} \mathrm{S}$, with salinity equal to $36.5 \mathrm{psu}$ for the climatology and 35 psu for the REF model.

However, the salinity along the coast is lower in the model than in the climatology, with differences up to 3 psu in the Congo plume and more than 7 psu in the Bight of Biafra. This discrepancy is at least partly due to the lack of observations near the coast (see Figure 1 of Da-Allada et al (2013a)) and the low resolution of the climatology: $0.5^{\circ}$, with a smoothing radius of $300 \mathrm{~km}$ (Gaillard et al 2009). Note that new satellite observations (Tzortzi et al 2013) show a lower salinity 
along the coast than the climatology, and a stronger connection between the low salinity waters of the Congo and the Bight of Biafra, in agreement with the model.

The SSS from our REF experiment is also compared in Figure 4 to the available SSS data from the PIRATA mooring at $0^{\circ} \mathrm{S}-0^{\circ} \mathrm{E}$ and also with the short record (less than one year) at $6^{\circ} \mathrm{S}-8^{\circ} \mathrm{E}$ (Bourlès et al 2008). Like the SST, the SSS in the Gulf of Guinea presents a strong seasonal cycle along the equator and offshore the coast at $6^{\circ} \mathrm{S}$ (Dessier and Donguy 1994; Eisma and Van Bennekom 1978). Along the equator, the model reproduces the seasonal cycle quite well, albeit with a larger seasonal amplitude (about $2 \mathrm{psu}$ in the model and closer to $1.8 \mathrm{psu}$ in the data). The model shows a phase shift with respect to the observations for the salinization phase in spring for years 2001 and 2006 , but not for the other years. At $6^{\circ} \mathrm{S}$ the model seems to underestimate the decrease in salinity observed in november 2006 .

\subsubsection{Stratification and mixed layer depth}

The stratification of our model in the Gulf of Guinea is too strong compared with the ARV09 climatology, for both temperature and salinity (Figure 5). If the thermocline appears a little bit too sharp, the main concern about stratification results from the salinity between 0 and 60 meters depth. Indeed, the model is $0.5 \mathrm{psu}$ fresher than the climatology at the surface (this is due to lower values near the coast as shown in Figure 3) and 0.15 psu saltier at $40 \mathrm{~m}$ depth. In the model, the salty waters carried by the Equatorial undercurrent below the surface layer in the Gulf of Guinea are not sufficiently eroded by mixing with the overlying freshwaters in comparison with observations (Kolodziejcyk et al 2013). In setting up the model, we have tried to adjust vertical mixing parameters (such as the background viscosity and diffusivity of the TKE mixing model) but we have not 
been able to improve this model bias. This strong vertical gradient in the model can influence the exchanges between the surface and subsurface layers.

For the mixed layer budgets, the capability of the model to reproduce correctly the spatial structure of the mixed layer and its temporal evolution is of particular importance. Following the recommendations of de Boyer Montegut et al (2004) for tropical regions, we use a $0.03 \mathrm{~kg} \cdot \mathrm{m}^{-3}$ density criterion to define the mixed layer depth in the model. The mean state of the mixed layer in our REF experiment is compared to the de Boyer Montegut et al (2004) climatology, using the 2008 update, in Figure 6. Both climatology and REF present shallow mixed layer depths along the eastern coast, particularly in the Bight of Biafra and in the region of the Congo plume with an averaged depth of 10 to 12 meters. Both also depict a deepening of the mixed layer in the region where the Guinea Current flows, around $2^{\circ} \mathrm{N}$, between the western boundary and $5^{\circ} \mathrm{E}$. In this region, the mixed layer depth is equal to $26 \mathrm{~m}$ on average. Finally, both model and observations present a shallower mixed layer along the equator than in the surrounding regions; however, this shallowing is exaggerated in the model. This can be explained by the strong stratification (Figure 5) which occurs along the equator more than in the rest of the basin. A similar discrepancy happens along the southern coast, between 13 and $6^{\circ} \mathrm{S}$, with a very shallow mixed layer in the model compared to the climatology. However, the lack of observations in this region make it difficult to conclude that the model is deficient in this area. The temporal variations of the mixed layer will be discussed in section 4.2 and are thus not presented here. 


\section{3 freshwater forcing and SSS variability}

\section{1 freshwater input in the eastern Gulf of Guinea}

Table 1 provides the respective volumes of precipitations and river runoffs in our two regions of interest, the Bight of Biafra and the Congo plume (black boxes on Figure 1) as well as for the Gulf of Guinea domain covered by our $1 / 12^{\circ}$ grid. The two regions concentrate $87 \%$ of the $80 \mathrm{mSv}$ discharged by rivers in the Gulf of Guinea, but they receive only $30 \%$ of the $140 \mathrm{mSv}$ of precipitations over the region.

In the Bight of Biafra, both precipitations and river runoffs present the same mean volume flux, equal to $27 \mathrm{mSv}$. South of the equator, the Congo represents $76 \%$ of the freshwater discharge (44 mSv against $14 \mathrm{mSv}$ for precipitations) and even the minimum discharge that occurs in August (33 mSv) is higher than the maximum discharge due to precipitations (31 mSv during April). In addition, the seasonal variations of each source of freshwater differ, depending on the region (Figure 7): semi annual for precipitation and river runoffs in the Bight of Biafra, semi annual for the Congo discharge and annual for precipitations south of the equator.

In the Biafra box in the northern hemisphere, the semi annual evolution of both precipitations and river runoffs (Figure 7) is associated with the African monsoon. Indeed during April, the maximum of precipitations is related to the northern displacement of the Inter Tropical Convergence Zone (ITCZ) which moves from the ocean to sub Saharan regions over the continent (Philander et al 1996). When the ITCZ goes back to its most southerly position over the ocean around November, a second intensification of precipitations occurs (Redelsperger et al 
2006). In between, around August, precipitations over the ocean are minimum when the monsoon front is in its most northerly position. Due to the time needed for precipitations over the continent to reach the ocean, the maximum runoff occurs five months later, during September/November. Contrary to the precipitations over the ocean, precipitations that cover the river catchment area present only annual variations (Mahé and Olivry 1999), which explain the weaker semi annual cycle of the runoffs compared with precipitations.

In the Congo box, the seasonal variation of the runoffs is relatively weak. Indeed, due to its huge catchment area, which covers both hemisphere in the central Africa (Laraque et al 2001), the Congo river is influenced by rainfall seasons in both hemispheres. As a consequence, it has always a part of its basin under high precipitations, which explains its important discharge equal to $44 \mathrm{mSv}$ on average. Because of the alternation in the rainfall seasons, the seasonal cycle of the river appears semi-annual, with a maximum discharge of $60 \mathrm{mSv}$ occurring in December and a weaker relative maximum in May. Precipitations over this region follow an annual cycle and are very weak from May to October.

\subsection{Sensitivity experiments on freshwater forcing}

To clarify the respective influence of precipitations and river runoffs on the spatial structure and variations of the surface salinity we have performed two sensitivity experiments. Based on our REF experiment, we perform a first simulation forced by precipitation only (PRECIP) where river runoffs have been turned off. In the second simulations (RUNOFF), precipitations have been turned off and it is thus forced by river discharges only. As we remove a large part of the freshwater input 
in these sensitivity tests, they are subject to a larger drift relative to the observed climatology. An adjustment is necessary during the first years of these runs to eliminate the low salinity water masses in the Bight of Biafra and offshore Angola that cannot be maintained with only a part of the observed freshwater input. To speed up this adjustment, we use a new initial state where the salinity in the surface layer in the Bight of Biafra and offshore Angola is set to the mean value of the SSS in the Gulf of Guinea. In addition, each simulation is integrated twice longer than REF by repeating the forcing from 1990 to 2006. Only the second integration is analysed.

Figure 8 shows the mean SSS from 1995 to 2006 for the PRECIP and RUNOFF experiments, with only precipitations (a) and river runoffs (b) respectively. The mean SSS on this figure must be compared with the mean SSS of our REF simulation on Figure 3b to better appreciate the influence of each source of freshwater. First, the meridional structure of the SSS, visible on both the climatological data and our REF simulation (Figure 3) can be explained by the meridional structure of the precipitations as already noticed by Yoo and Carton (1990). However, the PRECIP simulation clearly demonstrates that the desalinization in the Bight of Biafra is partly due to the large amount of precipitations discharged in this region (27 $\mathrm{mSv}$ on average). Our test shows that the contribution of the precipitations to the salinity anomaly can reach $3.5 \mathrm{psu}$, to compare with the $7.5 \mathrm{psu}$ of the REF case (differences between the Bight and the open ocean around $5^{\circ} \mathrm{E}$ ). This test also confirms the negligible role of precipitations south of the Equator as no desalinization can be observed in the Congo box, as expected from Table 1. Second, the RUNOFF simulation demonstrates the importance of the river runoffs to explain both the spatial structure of the SSS in the eastern part of the Gulf 
of Guinea and the amplitude of the desalinization compared to the open ocean. River runoffs contribute for 4 psu in the Bight of Biafra. As expected, they explain more than $90 \%$ of the desalinization in the Congo box, with an amplitude equal to $7.5 \mathrm{psu}$ (close to REF). In addition, even without precipitation to support the desalinization south of the equator, we find that the Congo plume can spread to $5^{\circ} \mathrm{E}$, practically the same extension as in the REF case.

Let us study the seasonal variability of SSS for each of the sensitivity experiments. A mean seasonal cycle is constructed by computing 12 monthly means over the period 1995-2006, and the seasonal amplitude is estimated as the difference between the maximum and minimum monthly salinity at each location. A map of the seasonal amplitude for our REF experiment is shown in Figure 9a. The highest variability occurs along the coast (up to $8 \mathrm{psu}$ ), where huge river discharges take place : in the Bight of Biafra north of equator and in the region of the Congo plume. Indeed, this map of seasonal amplitude has guided our choice of the target regions presented in Figure 1. The maximum seasonal amplitude is larger in the model compared with the in-situ climatology, but it is close to the amplitude revealed by the first satellite observations of SSS (Tzortzi et al 2013). The seasonal variability decreases rapidly with the distance to the coast. Indeed, offshore of a 2 to $3^{\circ}$ width band along the coast, the seasonal amplitude reaches only $2 \mathrm{psu}$. The maximum of variability takes place in the Congo plume region, where the desalinization is based upon only one source of freshwater and where the highest input is concentrated on a small region. Despite a lower river discharge inflow (Table 1), the region of high variability around the Bight of Biafra is the most expanded.

In the PRECIP case (Figure 9c), we can observe that precipitations force really limited SSS variations with a maximum of $2.5 \mathrm{psu}$. Surprisingly, the most 
important variability takes place near $3^{\circ} \mathrm{S}$ between the Bight of Biafra and the Congo plume region, where precipitations are not the strongest (see for example Figure 3 of Da-Allada et al (2013a)). For the RUNOFF case (Figure 9d), some features appear similar to REF. In particular, the variability in the Congo plume region is of the same order, around $8 \mathrm{psu}$, concentrated along the coast, decreasing rapidly offshore. In the northern part of the basin, around the Bight of Biafra, the variability is present, although lower and not as extended spatially as in REF.

Figure $9 \mathrm{~b}$ shows the sum of the variability of the PRECIP and RUNOFF experiments. The resulting map is similar to REF at first order, capturing the two regions of maximum variability as well as their amplitude. Differences appear though, demonstrating that the full solution cannot be constructed from a linear response to either forcing separately. The variability is larger along the northern coast in the region of the Guinea Current for PRECIP+RUNOFF compared to REF, but lower at the equator and south of it along the African coast. These differences are due to nonlinear effects of the dynamics as well as to the different phases of the seasonal variations of precipitations and runoffs.

\section{Mixed layer budget for salinity}

\subsection{Methodology}

Following the recent work of Da-Allada et al (2013a) on mixed layer budget for salinity in the Tropical Atlantic using observations, we perform mixed layer salinity budget with our REF experiment. We use the methodology developed by Vialard et al (2001) but applied to the salinity according to the Equation 1 (and using the $<$. $>$ operator defined in Equation 2 for vertical integration) with $S$ the 
mixed layer salinity, $u, v$ and $w$ the zonal, meridional and vertical velocities, $D_{l}$ the horizontal diffusive operator, $h$ the mixed layer depth, $E$ the evaporation, $P$ the precipitations and $R$ the river runoffs.

$$
\begin{aligned}
\partial_{t} S= & \underbrace{\left.-<u \partial_{x} S+v \partial_{y} S>+<D_{l}(S)\right\rangle}_{A} \\
& \underbrace{+w_{z=h}\left(\bar{S}-S_{z=h}\right)+\frac{k \partial_{z} S_{z=h}}{h}-\frac{1}{h} \frac{\partial h}{\partial t}\left[S_{z=0}-S_{z=h}\right]}_{B} \\
& +\underbrace{\frac{1}{h}(E-P-R) S S S}_{C}
\end{aligned}
$$

$$
<x>=\frac{1}{h} \int_{0}^{h} x d z
$$

The terms of the Equation 1 are grouped following Vialard et al (2012): the vertically averaged horizontal advection and diffusion (A), the vertical advection, mixing and entrainment (B) and finally the forcing terms : evaporation, precipitations and river runoffs $(\mathrm{C})$. A represents the horizontal transport of salt between the different regions. As the horizontal diffusion is negligible compared to the horizontal transport (Berger 2012), this term is referenced as "advection" hereafter. B represents the exchanges between the surface and the subsurface occurring across the mixed layer. The entrainment, which depicts the mixing effect due to the variations of the mixed layer depth, is computed as a residual to close the budget at each time step. The entrainment of Da-Allada et al (2013a) corresponds to our B term. Finally, C represents the freshwater fluxes across the surface. All these terms have been evaluated for the two coastal regions with the highest SSS variability (Figure 9): the Bight of Biafra and the Congo Plume, which appear as black boxes 
on Figure 1. Budgets are evaluated on-line and archived over successive 5-days periods.

4.2 Results

\subsubsection{The Bight of Biafra}

Before considering the mixed layer salinity balance, let us describe the seasonal cycle in our model. For this purpose, Figure 10 shows the seasonal cycle of the mixed layer salinity, the salinity below the mixed layer and the mixed layer depth in the model and observations. The bottom panel shows the seasonal cycle of vertical velocity in the model. In this region, the REF experiment underestimates the mixed layer salinity compared to the ARV09 climatology, with a bias reaching 2 psu. In addition the model presents a 2 months lag with the climatology when the salinization occurs from May to August (Figure 10a). It is interesting to note that using a different climatology and a different method, Da-Allada et al (2013a) obtain a similar lag in the salinity variations (although they have no bias); it is unclear whether the phase lag comes from similar deficiencies (in forcings or in the climatology) or from independent errors in the two calculations. Apart from these issues, the annual cycle is correctly reproduced in our model, with two maxima. The model also reproduces in a satisfying manner the evolution of the mixed layer, which is very shallow from December to June (12 $\mathrm{m}$ on average) when the salinity is low and deepens as the salinity increases from June to September.

The vertical velocity (Figure 10c) is positive during most of the year. This may seem surprising, considering that the Ekman transport due to the trade winds generates downwelling north of the equator along the coast of the Gulf of Guinea 
(see the map of Ekman pumping in Figure 12 of Giordani and Caniaux (2011)).

However our model is in agreement with the vertical velocity estimate of Giordani and Caniaux (2011), which is positive in most of the Bight of Biafra region due to the contribution of nonlinear terms. Thus vertical advection, on average, makes the mixed layer saltier. However, vertical advection cannot cause the increase in salinity from May to August, because vertical velocity decreases during that period, due to the increased downwelling tendency because of the intensification of trade winds (Giordani and Caniaux 2011). From May to August, when the mixed layer salinity increases, the mixed layer depth increases and the salinity 10 meters below decreases (Figure 10a): this is consistent with vertical mixing. It can be explained by an intensification of the winds, causing larger vertical shears and turbulent fluxes of momentum (Giordani and Caniaux 2011). Note that in the climatology, this link between salinization and mixed layer thickness does not exist, as the deepening of the mixed layer occurs 3 months after the increase of the salinity. Later in the year, from September to December, the model salinity decreases during a time where vertical velocities intensify, which means that the mixed layer shallowing and reduced vertical mixing are the main causes of this freshening.

The seasonal cycle of the salinity budget (Equation 1) is shown in Figure 11a. The freshwater fluxes (forcing, green curve) always contribute to diminish the salinity as the evaporation never compensates the precipitations and river runoffs. The forcing does not explain the salinity tendency, whatever the period we are interested in and contrary to the proposals of Dessier and Donguy (1994), Delcroix et al (2005) and Reverdin et al (2007). On the other hand, these results agree with 
Da-Allada et al (2013a) as they demonstrate the weak influence of the freshwater forcing in the Gulf of Guinea.

The most important contributions to the salinity tendency come from the dynamics. Indeed, both the advection and the subsurface contributions are on average higher than the forcing term by an order of magnitude (Figure 11a). They reach their maximum values from May to June with -1.5 psu.month ${ }^{-1}$ on average for the advection and up to 2 psu.month ${ }^{-1}$ for subsurface mechanisms. These value are twice the ones of Da-Allada et al (2013a) for the Gulf of Guinea, but it is not surprising as we have higher salinity gradients in a smaller region, increasing the importance of the dynamics.

To quantify the contribution of each mechanism and determine which one of them drives the intraseasonal to seasonal tendencies over the 1995-2006 period, we computed monthly linear regression coefficients for advection, subsurface processes and forcing. With $X_{t}=X_{a d v}(t)+X_{s u b}(t)+X_{f}(t)$ the total salinity tendency, equal to the sum of its contributors, the linear regression coefficient $\alpha_{i}$ of $X_{i}$ on $X_{t}$ can be estimated following Equation 3:

$$
\alpha_{i}=\operatorname{cor}\left(X_{i}, X\right) * \operatorname{stdev}\left(X_{i}\right) / \operatorname{stdev}(X)
$$

In the REF experiment, the horizontal advection drives the salinity tendency variability (Figure 11, bottom panel). Indeed, with a regression coefficient going from 0.75 to 1.5 , the advection is the main driver of the total variability. The regression coefficient is larger than one from october to march because the variance of the advection is larger than the variance of the total tendency. During that period, on the contrary, the subsurface processes damp the evolution of the salinity in the mixed layer, as shown by the opposite phases of the total and subsurface tenden- 
cies from September to March (Figure 11, top panel) and the negative regression coefficient (Figure 11, bottom panel). During the salinization period between May and August, the freshening tendency due to horizontal advection progressively decreases while the subsurface salinization remains always more important, linked with vertical mixing as noted above. Again this is consistent with Da-Allada et al (2013a) who find that entrainment explains the positive tendency of the salinity. Nevertheless, even in May-August, horizontal advection explains more of the tendency (the regression coefficient is lower for subsurface processes). This is due to the presence of high frequency variability in the total tendency as well as in the horizontal advection term, while subsurface processes vary on longer time scales.

\subsubsection{Congo Plume}

In this region, the REF experiment reproduces quite well the evolution of the annual salinity in the mixed layer (Figure 12a) with little bias nor phase shift compared with observations. The salinity increase occurs earlier than in the Bight of Biafra (April-June), followed by weaker variations from July to September. The mixed layer in the model is too shallow compared to the climatology of de Boyer Montegut et al (2004) but it seems more similar to the one of Giordani and Caniaux (2011). Like in the Bight of Biafra, the deepening of the mixed layer begins when the salinization occurs from April to August, but it remains limited to 3 meters contrary to the Bight of Biafra where the depth of the mixed layer doubles. On Figure 12a, we can also observe that in the Congo plume region region, the salinities in the mixed layer and 10 meters below it evolve similarly, arguing for lower exchange between surface and subsurface layers. Indeed, the deepening of the mixed layer from May to August (Figure 12b) does not corre- 
455

spond to a decreasing subsurface salinity, contrary to the Bight of Biafra. Vertical velocities are almost always positive with a strong semi-annual cycle, very similar to the Bight of Biafra. In the Congo plume however, the increase of vertical velocity from February to June coincides with the initial phase of salinization, which suggests that the strong increase of the mixed layer salinity can be due to a direct transport of salt from the subsurface, consistent with upwelling dynamics as the trade winds intensify (Verstraete 1992).

Figure 13 presents the different terms of Equation 1 for the Congo Plume region. As in for the Bight of Biafra, the freshwater forcing is weaker than the other terms, in good agreement with Da-Allada et al (2013a). The salinity tendency results from a balance between horizontal advection (which carries salt away from the region) and the vertical processes that bring salt into the mixed layer. The seasonal cycle of advection and tendency is smoother than in the Bight of Biafra (there is less high frequency variability). Regarding the subsurface processes, time series of the advective and diffusive contributions show that the vertical advection is relatively more important than in the Bight of Biafra (Berger 2012).

The regression of horizontal and subsurface processes with the tendency (Figure 13, bottom panel) shows that in the Congo plume region, both processes add up to force the total tendency most of the year. Horizontal advection always contributes positively to the total tendency of the mixed layer salinity. Subsurface processes damp the tendency (negative regression coefficient) only during the months of September and October, when the vertical velocity weakens and the mixed layer deepens. Subsurface dynamics contribute equally and sometimes more to the variability than the horizontal advection, from May to August. During this period, as the advective tendency goes to zero the subsurface dynamics intensify 
and transport more and more salt to the mixed layer from the subsurface, causing the strong salinization.

\subsection{Contribution of transient dynamics to horizontal advection}

Comparing the salinity tendency on Figures 11 and 13, we find a higher variability in the Bight of Biafra. This leads us to suspect that the correlation of transient fluctuations of velocity and salinity may be an important contribution to the budget. To assess this contribution, we decompose the salinity tendency due to horizontal advection (here $\partial_{t} S_{a d v}$ ) in two terms :

$$
\partial_{t} S_{a d v}=<\partial_{t} S>_{m o n t h}+\partial_{t} S_{r e s}
$$

In this equation, $\partial_{t}\langle S\rangle_{\text {month }}$ represents the part of the horizontal advection due to the seasonal mean velocity and seasonal mean salinity. To compute it, we first apply a low pass filter on the mean seasonal cycle of the zonal and meridional velocities as well as the mixed layer salinity to remove all the variability at higher frequencies than a month. This smoothed seasonal cycle is noted $<>_{\text {month }}$. The seasonal advection is thus determined off-line with :

$<\partial_{t} S>_{\text {month }}=-<U>_{\text {month }} \partial_{x}<S>_{\text {month }}-<V>_{\text {month }} \partial_{y}<S>_{\text {month }}$

The $\partial_{t} S_{r e s}$ represents the residual, with all the contributions other than the mean seasonal velocities and salinities: high frequency waves, eddies... It results from the difference between the on-line budget for the advection (A term of the Equation 1) and the off-line budget.

The results of these computations can be seen on Figure 14. In the Bight of Biafra, the residual (eddy) term dominates the horizontal advection tendency while 
500

in the Congo Plume the total advection is almost entirely due to the mean seasonal cycle of velocity and salinity, underlying the dynamical differences between the two regions. This agrees with the model results of Guiavarc'h et al (2009) who point out that the surface Eddy Kinetic Energy (EKE) at periods between 10 and 20 days is much higher in the Bight of Biafra than in the Congo Plume. In their model, the surface intensification of EKE is due to the variability of the winds which is higher north of the equator than to the south. This surface intensification of EKE is validated at one location by current meter measurements that indicate an even higher surface EKE than the model (see Guiavarc'h et al (2009) Figure 7). Another reason for the high residual in Figure 14a is that our Bight of Biafra region encompasses the equator, where the 10-20 days variability is especially large. Offshore Angola and Gabon, the north-westward surface currents are spatially smooth and do not vary as much in direction, being the coastal part of the wind forced South Equatorial Current (Stramma and Schott 1999). As a consequence, the horizontal advection is mostly due to the mean seasonal component.

\section{Conclusions}

In this paper, we analyse the mechanisms of the intra-seasonal and seasonal variability of the SSS in the eastern Gulf of Guinea. We evaluate the importance of the different sources of freshwater using numerical modelling and we quantify the dynamical contribution to the SSS variability using mixed layer budgets for salinity. 
Our sensitivity experiments, forced by either runoffs or precipitations, emphasise the causal relationship between the water flux forcing and the SSS in the eastern Gulf of Guinea. It appears that the river runoffs, despite the fact that their volume represents only $38 \%$ of the total freshwater inflow, are necessary to explain the amplitude of the seasonal cycle of the SSS (which reaches 6 psu or more along the coast) while precipitations alone generate a weaker seasonal cycle with an amplitude of about 2 psu. However, these sensitivity studies, carried out with a fully nonlinear model, do not imply that there is a simple local relationship between the freshwater forcing and the SSS in a given region. Indeed, in a recent study based on satellite observations, Tzortzi et al (2013) failed to establish such a relationship for the Gulf of Guinea and suggested that advection and mixing must play a role locally to explain the spatial structure and the phase of the seasonal cycle.

Mixed layer budgets in the Bight of Biafra and the Congo plume demonstrate the importance of the dynamics, in good agreement with the recent findings of Da-Allada et al (2013a) and the hypothesis of Tzortzi et al (2013). In both the Bight of Biafra and the Congo plume region, the surface circulation is responsible for an offshore transport of coastal freshwater and thus tends to decrease the mixed layer salinity. The intensity of this transport depends on the amount of the river discharge and is logically minimum between June and August (Figures 7, 11 and 13). Thus the freshwater input appears as a limiting factor for horizontal advection, even though it does not drive directly the variability of the salt content in the mixed layer. The vertical physics, which are responsible for the salinization from May to August when the horizontal advection weakens, differ in each region. In the Bight of Biafra, the salt transport from the subsurface layers comes from 
547

an intensification of the mixing. In the Congo plume, the upwelling dynamics dominate the salinization, vertical advection representing the main contribution to the subsurface salt input. Overall, horizontal advection is the main driver of SSS variability in the Bight of Biafra, while vertical processes damp the variability, as demonstrated by a regression analysis. The picture is more complex for the Congo plume region, with horizontal advection and vertical processes both contributing positively to the SSS tendency during most of the year.

Finally, we have calculated separately the advective contributions due to the mean seasonal cycle of horizontal velocity and salinity. We have shown that this seasonal contribution explains the advection in the Congo plume. On the contrary, transient dynamics such as high frequency waves or eddies dominate the horizontal advection in the Bight of Biafra. The near equatorial position of the enclosed Bight of Biafra may explain this difference. A specific study of the variability and its contrast between the northern and southern part of the bight would be interesting, but it may require a higher resolution model.

Although our mixed layer budget agrees overall with the observation-based estimate of Da-Allada et al (2013a), there are differences in the strength of the different terms as well as in the details of the seasonal cycle. For example, the semi annual cycle of the SSS is much more pronounced in our model, which may be due to different forcings (we use precipitations from Large and Yeager (2009), while DaAllada et al (2013a) use precipitations from ERA-Interim). Recently, Da-Allada et al (2013b) have used the numerical model of Jouanno et al (2011) in order to study the inter-annual variability of salinity in the Gulf of Guinea. The seasonal cycle of their model presents differences with ours that will need to be investigated. For example, their SSS is closer to the climatology than ours, which may be due 
to different choices for the forcing or the vertical mixing parameterization. Despite the differences in the mean state of the two models, our main results regarding the seasonal budgets for the mixed layer salinity are consistent, which gives us confidence that they are robust. More in-situ and satellite observations are clearly needed to conduct more in-depth validations of these numerical models, at the process level. In the Congo plume region, the PIRATA mooring at $6^{\circ} \mathrm{S}-8^{\circ} \mathrm{E}$, now operational again, will provide extremely valuable long time series. Similar longterm observations are crucially needed in the Bight of Biafra.

Acknowledgements This work has been supported by grants from TOTAL, from INSU/LEFE and Mercator-Ocean. H. Berger was supported by Actimar, TOTAL and the CNRS; N. Perenne is supported by Actimar and A.M. Treguier by CNRS. Computations were done on the CAPARMOR computer at Ifremer as well as on the IDRIS center of GENCI in Orsay. We thank Jean Marc Molines and Raphael Dussin, the modelling team at LGGE, for their help to set up the NEMO-AGRIF model and providing the forcing conditions. We thank Fabienne Gaillard for providing her ARV09 climatology, Clement De Boyer Montegut for the climatology of mixed layer depth, Aiguo Dai for providing his runoff dataset and Bernard Bourles for providing us the PIRATA data. We particularly thank Jerome Vialard for his helpful suggestions about this work.

\section{References}

Barnier B, Madec G, Penduff T, Molines JM, Treguier AM, Le Sommer J, Beckmann A, Biastoch A, Böning C, Dengg J, et al (2006) Impact of partial steps and momentum advection schemes in a global ocean circulation model at eddy-permitting resolution. Ocean Dynamics 56(5-6):543-567

Berger H (2012) Origine des variations de la salinité de surface dans le Golfe de Guinée: Analyse saisonnière et interannuelle à partir d'un modèle numérique. PhD thesis, Universite de Bretagne Occidentale, Ecole Doctorale des Sciences de la Mer 
Blanke B, Delecluse P (1993) Variability of the tropical atlantic ocean simulated by a general circulation model with two different mixed-layer physics. Journal of Physical Oceanography 23(7):1363-1388

Blanke B, Arhan M, Lazar A, Prévost G (2002) A lagrangian numerical investigation of the origins and fates of the salinity maximum water in the atlantic. Journal of Geophysical Research: Oceans (1978-2012) 107(C10):27-1

Bourlès B, Lumpkin R, McPhaden MJ, Hernandez F, Nobre P, Campos E, Yu L, Planton S, Busalacchi AJ, Moura AD, et al (2008) The pirata program: History, accomplishments, and future directions. Bulletin of the American Meteorological Society

de Boyer Montegut C, Madec G, Fischer AS, Lazar A, Iudicone D (2004) Mixed layer depth over the global ocean: An examination of profile data and a profile-based climatology. Journal of Geophysical Research: Oceans (1978-2012) 109(C12)

Brodeau L, Barnier B, Treguier AM, Penduff T, Gulev S (2010) An era40-based atmospheric forcing for global ocean circulation models. Ocean Modelling 31(3):88-104

Da-Allada CY, Alory G, Penhoat Yd, Kestenare E, Durand F, Hounkonnou N (2013a) Seasonal mixed-layer salinity balance in the tropical atlantic ocean: Mean state and seasonal cycle. Journal of Geophysical Research: Oceans

Da-Allada CY, Penhoat Yd, Alory G, Jouanno J, Hounkonnou N (2013b) Modeled mixed layer balance in the gulf of guinea; seasonal and inter annual variability. Submitted to Ocean dynamic

Dai A, Trenberth KE (2002) Estimates of freshwater discharge from continents: Latitudinal and seasonal variations. Journal of hydrometeorology 3(6):660-687

Dai A, Qian T, Trenberth KE, Milliman JD (2009) Changes in continental freshwater discharge from 1948 to 2004. Journal of Climate 22(10):2773-2792

Debreu L, Blayo E (2008) Two-way embedding algorithms: a review. Ocean Dynamics 58(5$6): 415-428$

Delcroix T, McPhaden MJ, Dessier A, Gouriou Y (2005) Time and space scales for sea surface salinity in the tropical oceans. Deep Sea Research Part I: Oceanographic Research Papers $52(5): 787-813$ 
Dessier A, Donguy JR (1994) The sea surface salinity in the tropical atlantic between 10 s and 30 nseasonal and interannual variations (1977-1989). Deep Sea Research Part I: Oceanographic Research Papers 41(1):81-100

Eisma D, Van Bennekom A (1978) The zaire river and estuary and the zaire outflow in the atlantic ocean. Netherlands Journal of Sea Research 12(3):255-272

Ferry N, Reverdin G (2004) Sea surface salinity interannual variability in the western tropical atlantic: An ocean general circulation model study. Journal of Geophysical Research: Oceans (1978-2012) 109(C5)

Gaillard F, Autret E, Thierry V, Galaup P, Coatanoan C, Loubrieu T (2009) Quality control of large argo datasets. Journal of Atmospheric and Oceanic Technology 26(2):337-351

Giordani H, Caniaux G (2011) Diagnosing vertical motion in the equatorial atlantic. Ocean Dynamics 61(12):1995-2018

Giordani H, Caniaux G, Voldoire A (2013) Intraseasonal mixed-layer heat budget in the equatorial atlantic during the cold tongue development in 2006. Journal of Geophysical Research: Oceans

Guiavarc'h C, Treguier AM, Vangriesheim A (2008) Remotely forced biweekly deep oscillations on the continental slope of the gulf of guinea. Journal of Geophysical Research: Oceans (1978-2012) 113(C6)

Guiavarc'h C, Treguier AM, Vangriesheim A (2009) Deep currents in the gulf of guinea: along slope propagation of intraseasonal waves. Ocean Science 5(2):141-153

Hummels R, Dengler M, Bourlès B (2012) Seasonal and regional variability of upper ocean diapycnal heat flux in the atlantic cold tongue. Progress in Oceanography

Jouanno J, Marin F, Du Penhoat Y, Sheinbaum J, Molines JM (2011) Seasonal heat balance in the upper $100 \mathrm{~m}$ of the equatorial atlantic ocean. Journal of Geophysical Research: Oceans (1978-2012) 116(C9)

Kolodziejcyk N, Marin F, Bourles B, Berger H, Gouriou Y (2013) Seasonal to interannual variability of the Equatorial Undercurrent termination and associated salinity in the Gulf of Guinea. In revision, Journal of Geophysical Research

Laraque A, Mahé G, Orange D, Marieu B (2001) Spatiotemporal variations in hydrological regimes within central africa during the xxth century. Journal of Hydrology 245(1):104-117 
Large W, Yeager S (2009) The global climatology of an interannually varying air-sea flux data set. Climate Dynamics 33(2-3):341-364

Large WG, Yeager SG (2004) Diurnal to decadal global forcing for ocean and sea-ice models: The data sets and flux climatologies. National Center for Atmospheric Research

Levitus S (1986) Annual cycle of salinity and salt storage in the world ocean. Journal of physical oceanography $16(2): 322-343$

Madec G (2008) Nemo ocean engine. Note du pôle de modelisation, Institut Pierre Simon Laplace (Paris)

Mahé G, Olivry JC (1999) Assessment of freshwater yields to the ocean along the intertropical atlantic coast of africa (1951-1989). Comptes Rendus de l'Académie des Sciences-Series IIA-Earth and Planetary Science 328(9):621-626

Penduff T, Le Sommer J, Barnier B, Tréguier AM, Molines JM, Madec G, et al (2007) Influence of numerical schemes on current-topography interactions in 1/4 global ocean simulations. Ocean Science Discussions 4(3):491-528

Peter AC, Le Hénaff M, Du Penhoat Y, Menkes CE, Marin F, Vialard J, Caniaux G, Lazar A (2006) A model study of the seasonal mixed layer heat budget in the equatorial atlantic. Journal of Geophysical Research: Oceans (1978-2012) 111(C6)

Philander S, Gu D, Lambert G, Li T, Halpern D, Lau N, Pacanowski R (1996) Why the itcz is mostly north of the equator. Journal of Climate 9(12):2958-2972

Redelsperger JL, Thorncroft CD, Diedhiou A, Lebel T, Parker DJ, Polcher J (2006) African monsoon multidisciplinary analysis: An international research project and field campaign. Bulletin of the American Meteorological Society 87(12):1739-1746

Reverdin G, Kestenare E, Frankignoul C, Delcroix T (2007) Surface salinity in the atlantic ocean (30 s-50 n). Progress in Oceanography 73(3):311-340

Stramma L, Schott F (1999) The mean flow field of the tropical atlantic ocean. Deep Sea Research Part II: Topical Studies in Oceanography 46(1):279-303

Treguier AM, Barnier B, De Miranda A, Molines J, Grima N, Imbard M, Madec G, Messager C, Reynaud T, Michel S (2001) An eddy-permitting model of the atlantic circulation: Evaluating open boundary conditions. Journal of geophysical research 106(C10):22,115-22 
686

687

688

Tzortzi E, Josey S, Srokosz M, Gommenginger C (2013) Tropical atlantic salinity variability: New insights from smos. Geophysical Research Letters

Verstraete JM (1992) The seasonal upwellings in the gulf of guinea. Progress in Oceanography 29(1):1-60

Vialard J, Menkes C, Boulanger JP, Delecluse P, Guilyardi E, McPhaden MJ, Madec G (2001) A model study of oceanic mechanisms affecting equatorial pacific sea surface temperature during the 1997-98 el nino. Journal of Physical Oceanography 31(7):1649-1675

Vialard J, Drushka K, Bellenger H, Lengaigne M, Pous S, Duvel JP (2012) Understanding madden-julian-induced sea surface temperature variations in the north western australian basin. Climate Dynamics pp 1-16

Yoo JM, Carton JA (1990) Annual and interannual variation of the freshwater budget in the tropical atlantic ocean and the caribbean sea. Journal of physical Oceanography 20(6):831845 
Table 1 Mean volume of freshwater discharge in the different regions of the Gulf of Guinea.

The regions are the ones described in Figure 1. Precipitations come from the DFS4.3 product and river runoffs from Dai et al (2009).

\begin{tabular}{|c|c|c|c|c|c|c|}
\hline \multirow[t]{2}{*}{ Regions } & \multicolumn{3}{|c|}{ Precipitations (Sv) } & \multicolumn{3}{|c|}{ Coastal Runoffs (Sv) } \\
\hline & mean & $\max$ & $\min$ & mean & $\max$ & $\min$ \\
\hline Gulf of Guinea & 0.135 & 0.258 & 0.058 & 0.082 & 0.099 & 0.066 \\
\hline Bight of Biafra & 0.027 & 0.040 & 0.014 & 0.027 & 0.039 & 0.020 \\
\hline Congo region & 0.014 & 0.031 & 0.0001 & 0.044 & 0.060 & 0.033 \\
\hline
\end{tabular}




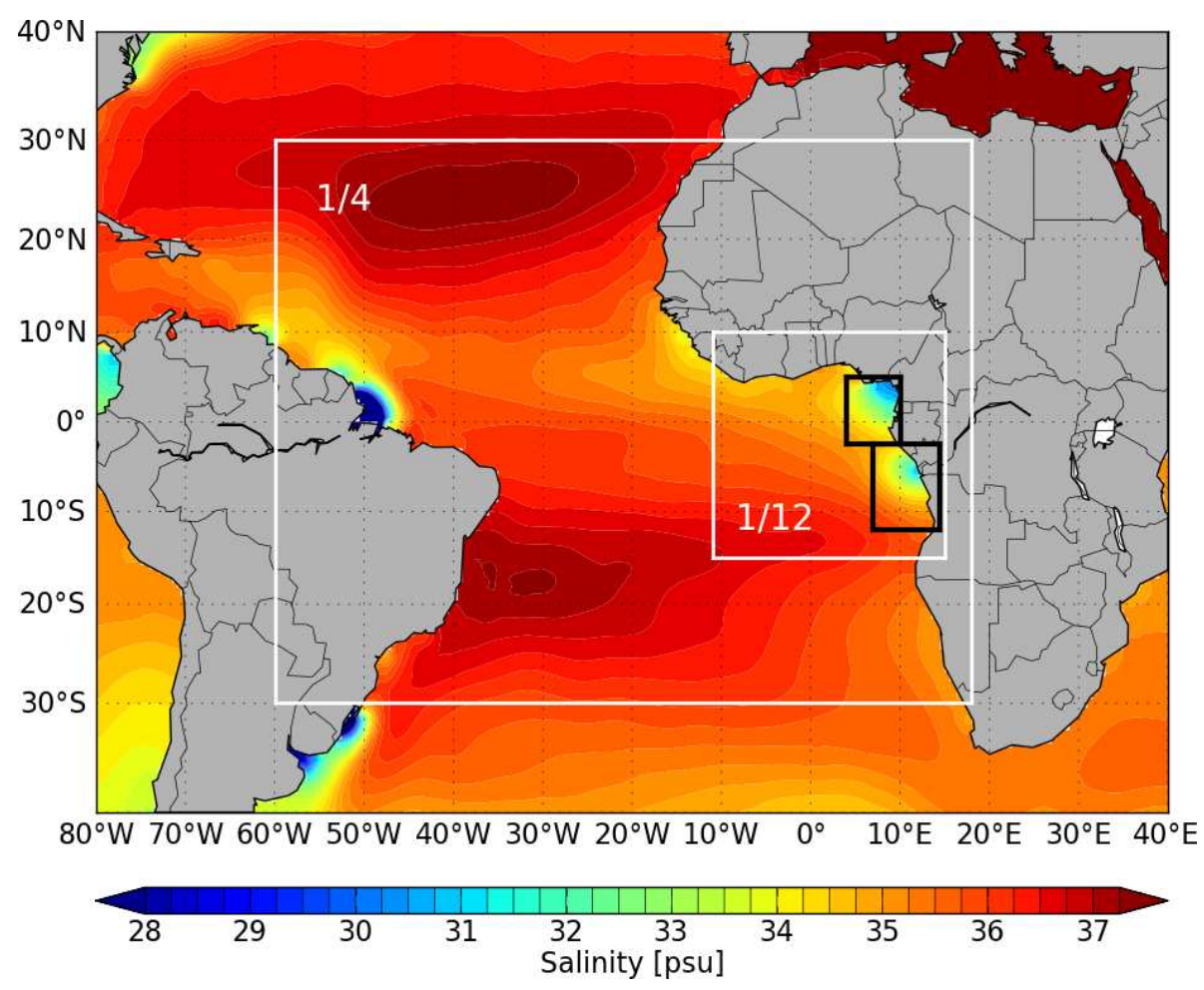

Fig. 1 Mean SSS for the tropical Atlantic from ARV09 climatology (Gaillard et al 2009). The models domains with $1 / 12^{\circ}$ and $1 / 4^{\circ}$ resolution used for this study are outlined in white, and the domains used for freshwater impacts and mixed layer budget analysis are indicated in black (Biafra box, north of the equator, and Congo box, south of the equator) 


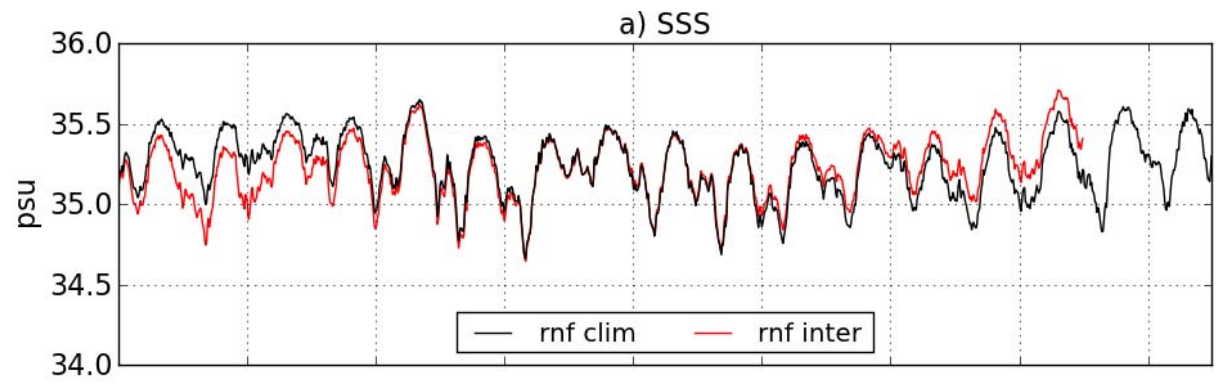

b) SSS anomalies

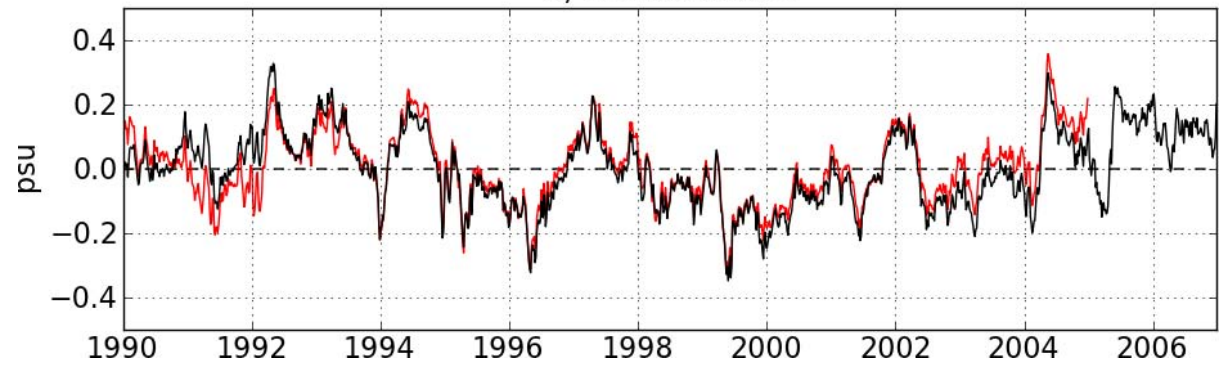

Fig. 2 a : Mean SSS of the model in the Gulf of Guinea $\left(1 / 12^{\circ}\right.$ domain of Figure 1$)$ using climatological (black) and inter-annual (red) runoffs from 1990 to 2006 (2004 for inter-annual). b: corresponding anomalies for climatological (black) and inter-annual (red) runoffs. The anomalies are computed using normalized time series where the long term trend has been removed. Climatological runoffs have been computed by averaging the inter-annual runoffs data of Dai et al (2009) from 1990 to 2004.
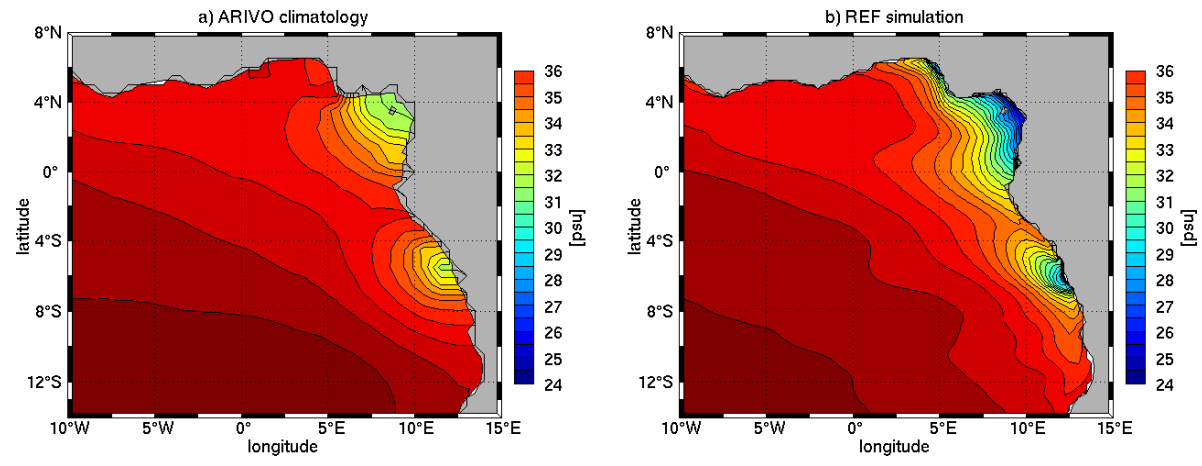

Fig. 3 Mean state of SSS in the Gulf of Guinea in the ARV09 climatology (Gaillard et al 2009) (a) and in the REF experiment from 1995 to 2006 (b). 

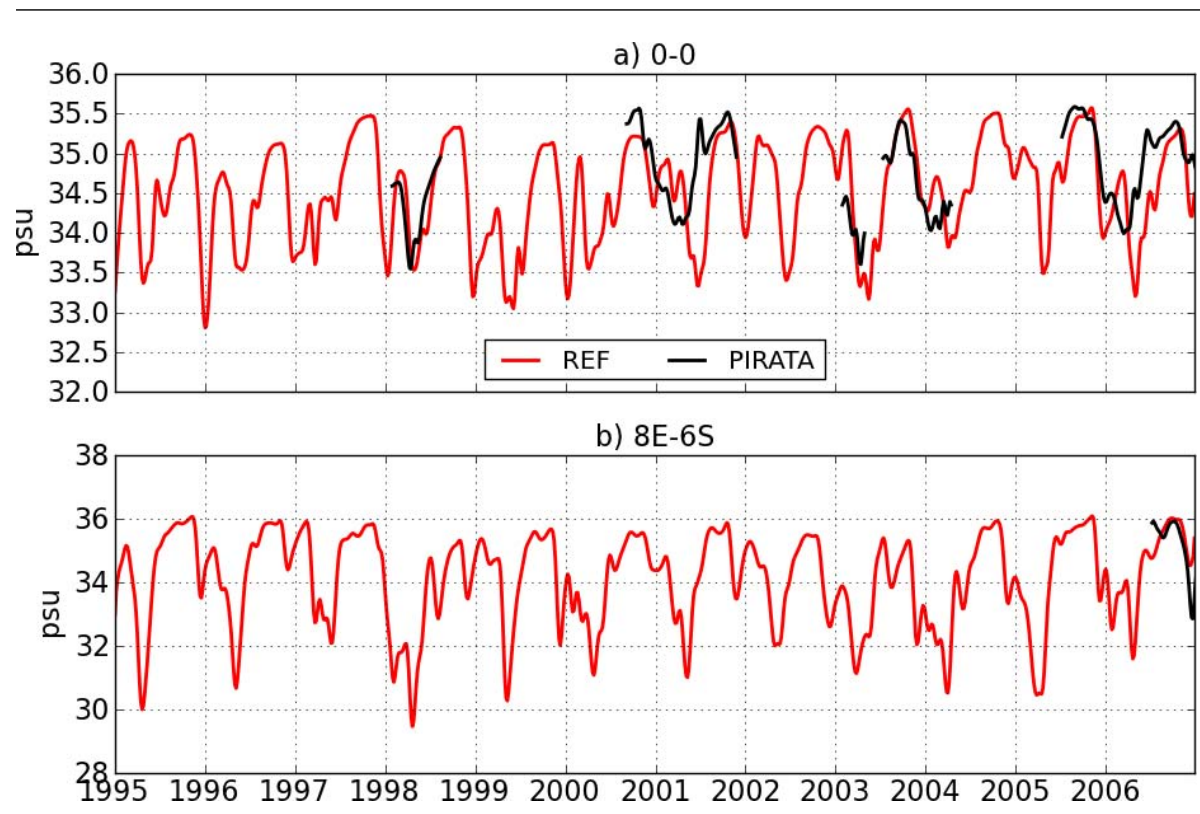

Fig. 4 Inter-annual series of the SSS on the positions of two PIRATA moorings in the Gulf of Guinea: at $0^{\circ} 0^{\circ}$ (a) and $8^{\circ} \mathrm{E} 6^{\circ} \mathrm{S}$ (b) for the REF experiment (red) and the PIRATA moorings observations (black) from 1995 to 2006. 
a)

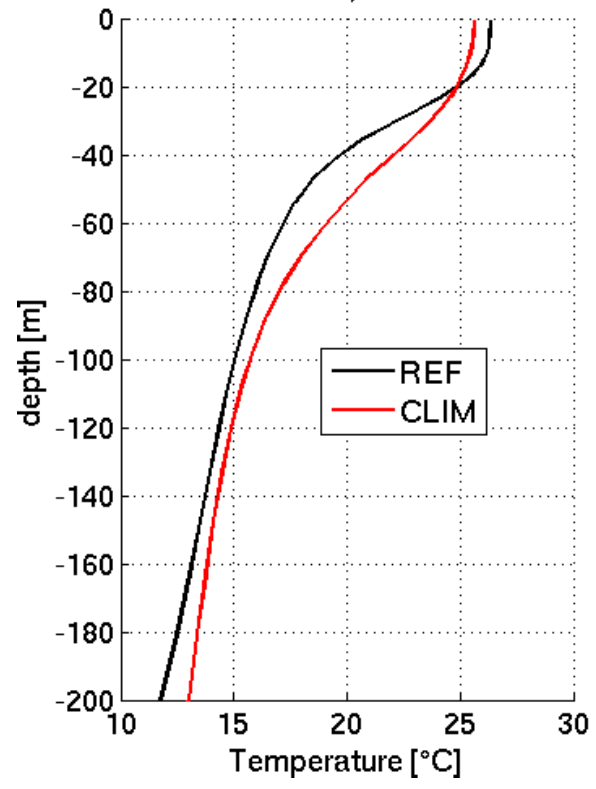

b)

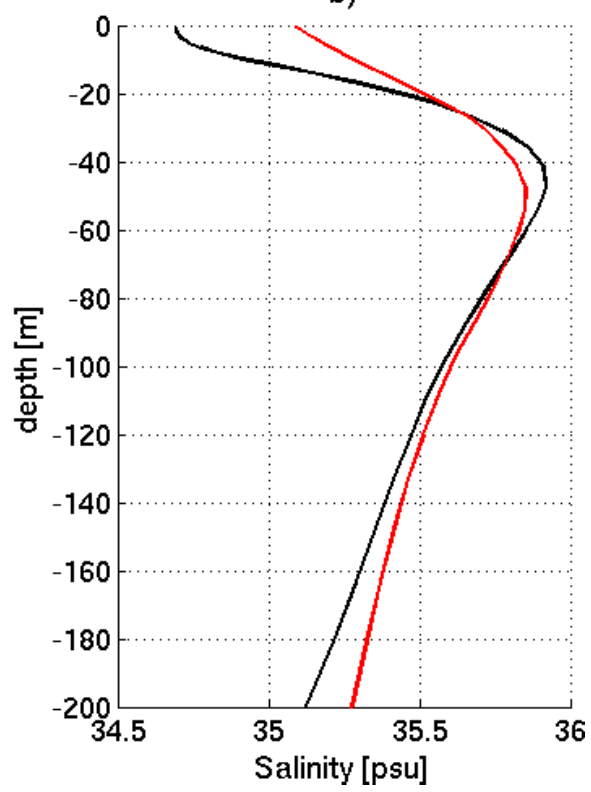

Fig. 5 Mean temperature (a) and salinity (b) profiles in the Gulf of Guinea from the surface to 200 meters in the ARV09 climatology (red) and the REF experiment from 1995 to 2006 (black). The domain used correspond to the $1 / 12^{\circ}$ domain visible on Figure 1 .
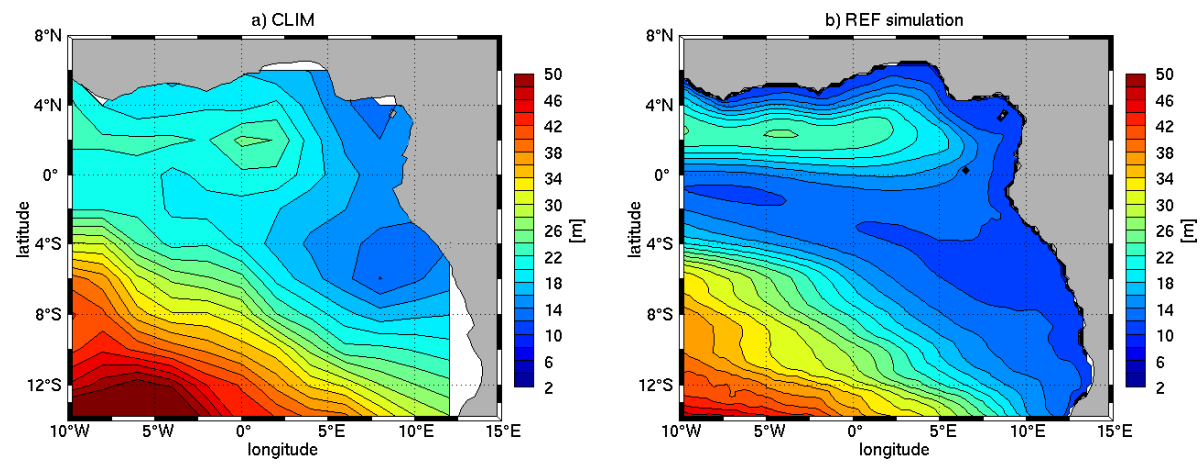

Fig. 6 Mean state of the mixed layer depth in the Gulf of Guinea in the climatology of de Boyer Montegut et al (2004) (a) and in the REF experiment from 1995 to 2006 (b). 


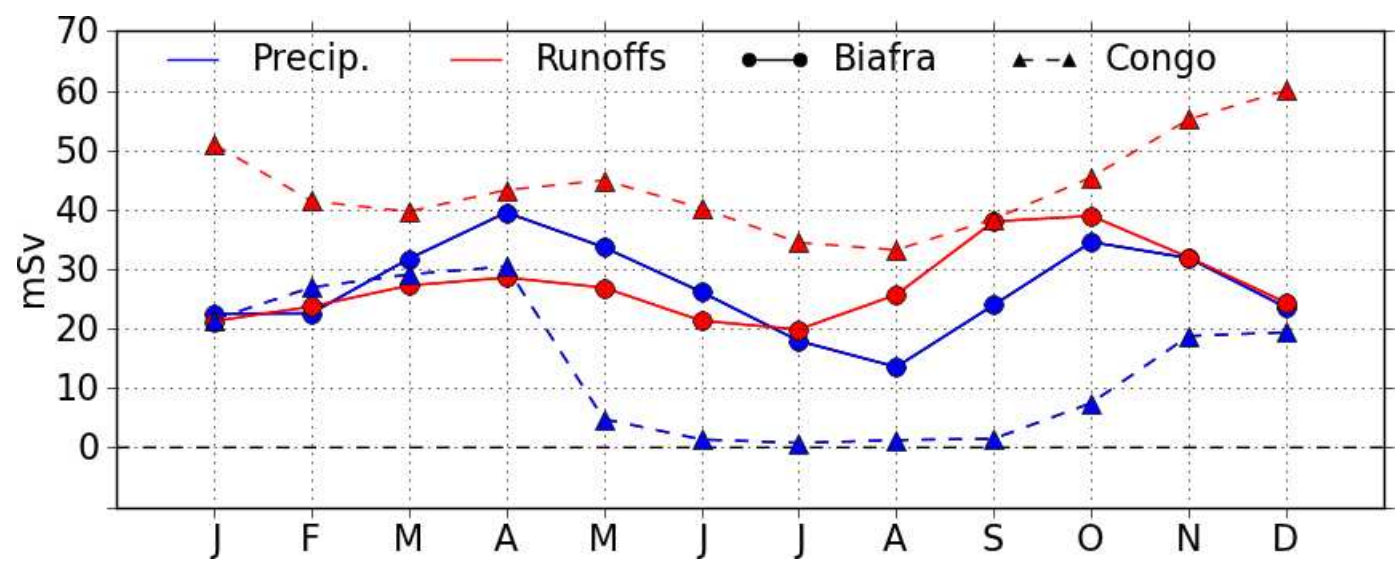

Fig. 7 Mean seasonal cycle of the freshwater input in the Biafra and Congo boxes (Figure 1). Precipitations and runoffs for each region appear as blue and red lines respectively. Data for the Bight of Biafra are marked by continuous lines with circles and data for the Congo plume are marked by dashed lines with triangles. Precipitations (GPCP) come from the Drakkar Forcing Set (Brodeau et al 2010) and the river runoffs from Dai et al (2009).
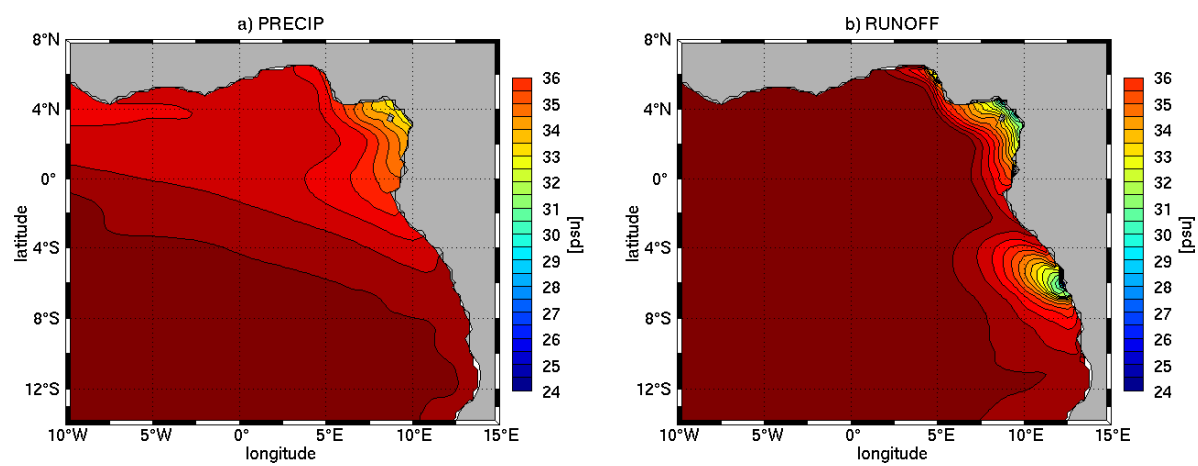

Fig. 8 Mean state of the SSS in the Gulf of Guinea in our PRECIP (a) and RUNOFF sensitivity experiments from 1995 to 2006. 

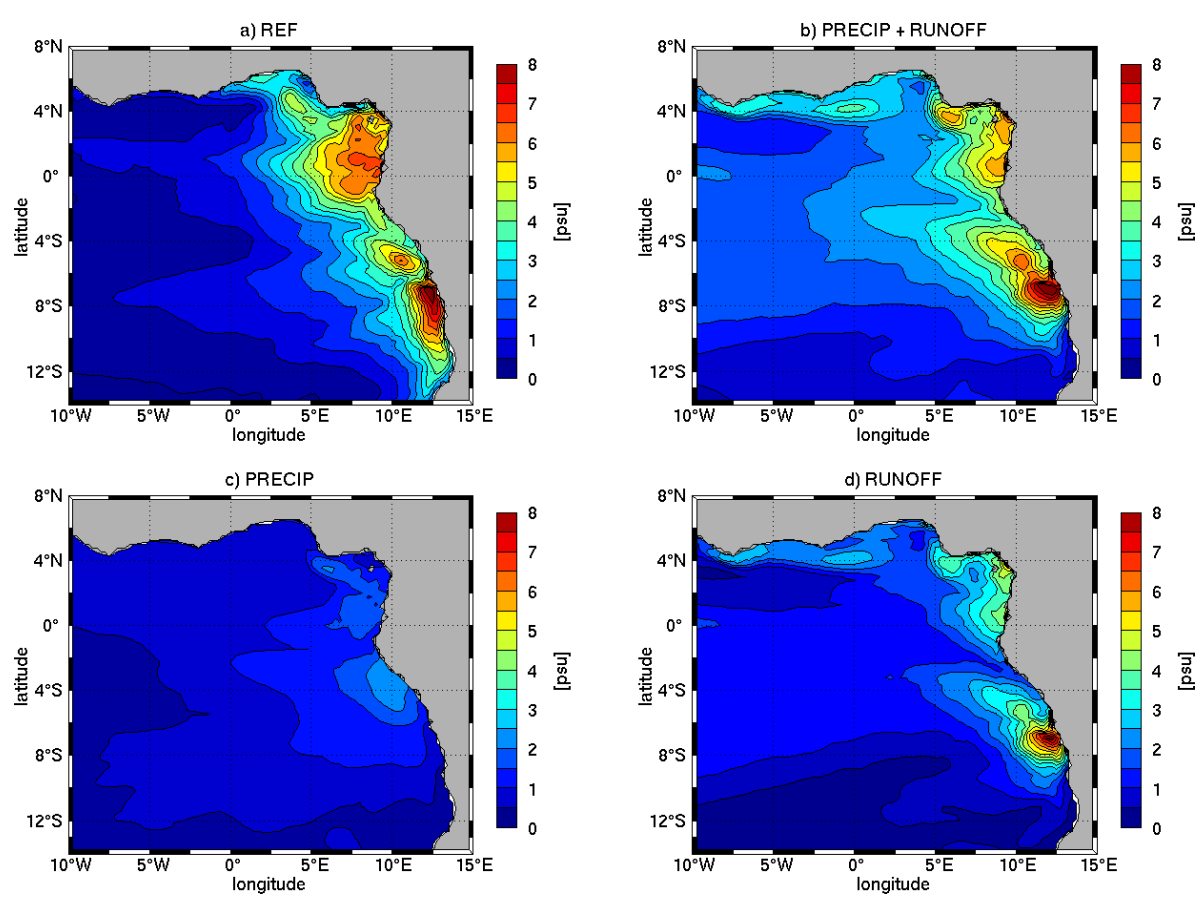

Fig. 9 Map of the SSS seasonal variability amplitude in the Gulf of Guinea. a) REF experiment, b) sum of the variability from PRECIP and RUNOFF experiments, c) PRECIP experiment, d) RUNOFF experiment. The seasonal amplitudes are computed at each grid point from a time series of monthly SSS from 1995 to 2006, by taking the difference between the maximum and the minimum monthly SSS for each year, and then averaging these amplitudes for all years. 


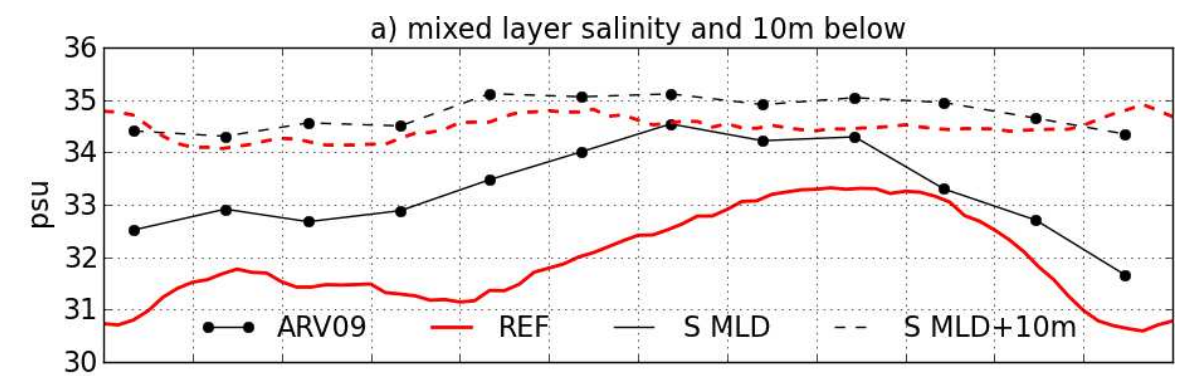

b) mixed layer depth
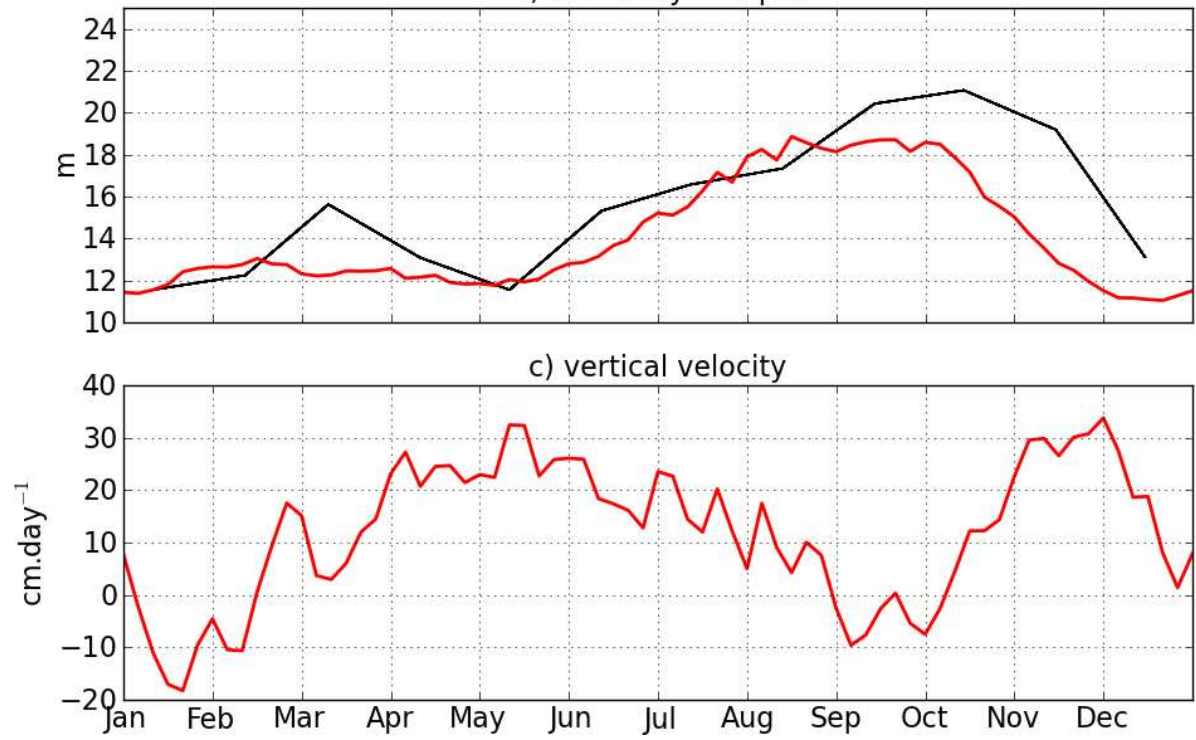

Fig. 10 Mean seasonal values of various fields computed from 1995 to 2006 in the Biafra box of Figure 1. a) Mean annual salinity in the mixed layer (continuous) and 10 meters below (dashed) in REF (red) and ARV09 (black). b) Mean annual evolution of the mixed layer depth in REF (red) and the climatology of de Boyer Montegut et al (2004) (black). c) Mean annual vertical velocity in the REF experiment. 

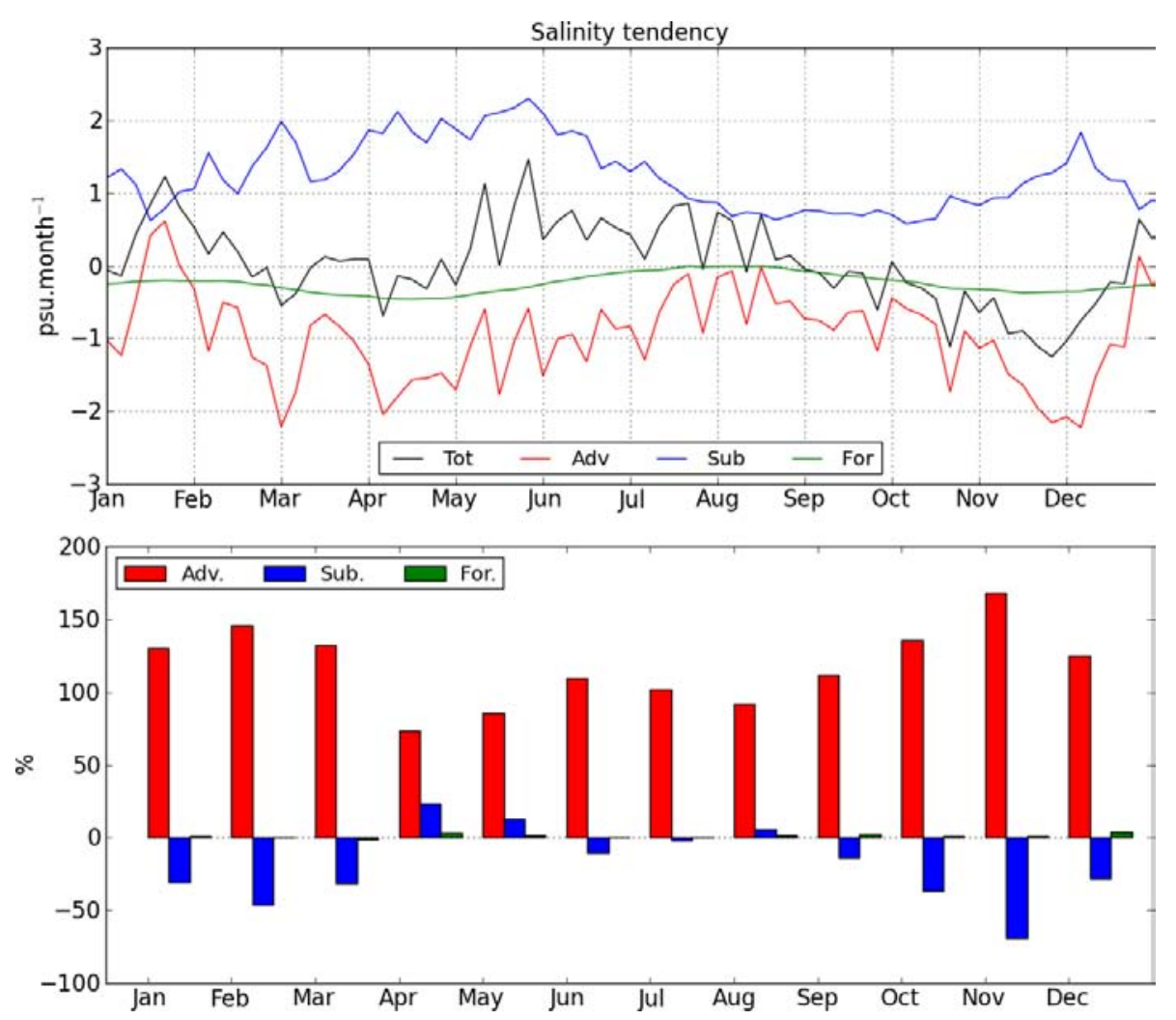

Fig. 11 Top : mean seasonal contributions to the mixed layer budget for salinity of the A, B and $\mathrm{C}$ terms of Equation 1. These contributions have been computed from 1995 to 2006 in the Biafra box of Figure 1. Bottom : monthly regression coefficients of the terms of Equation 1 computed using the Equation 3. On these figures, the total trend appears in black, the advection in red, the subsurface processes in blue and the forcing in green. 

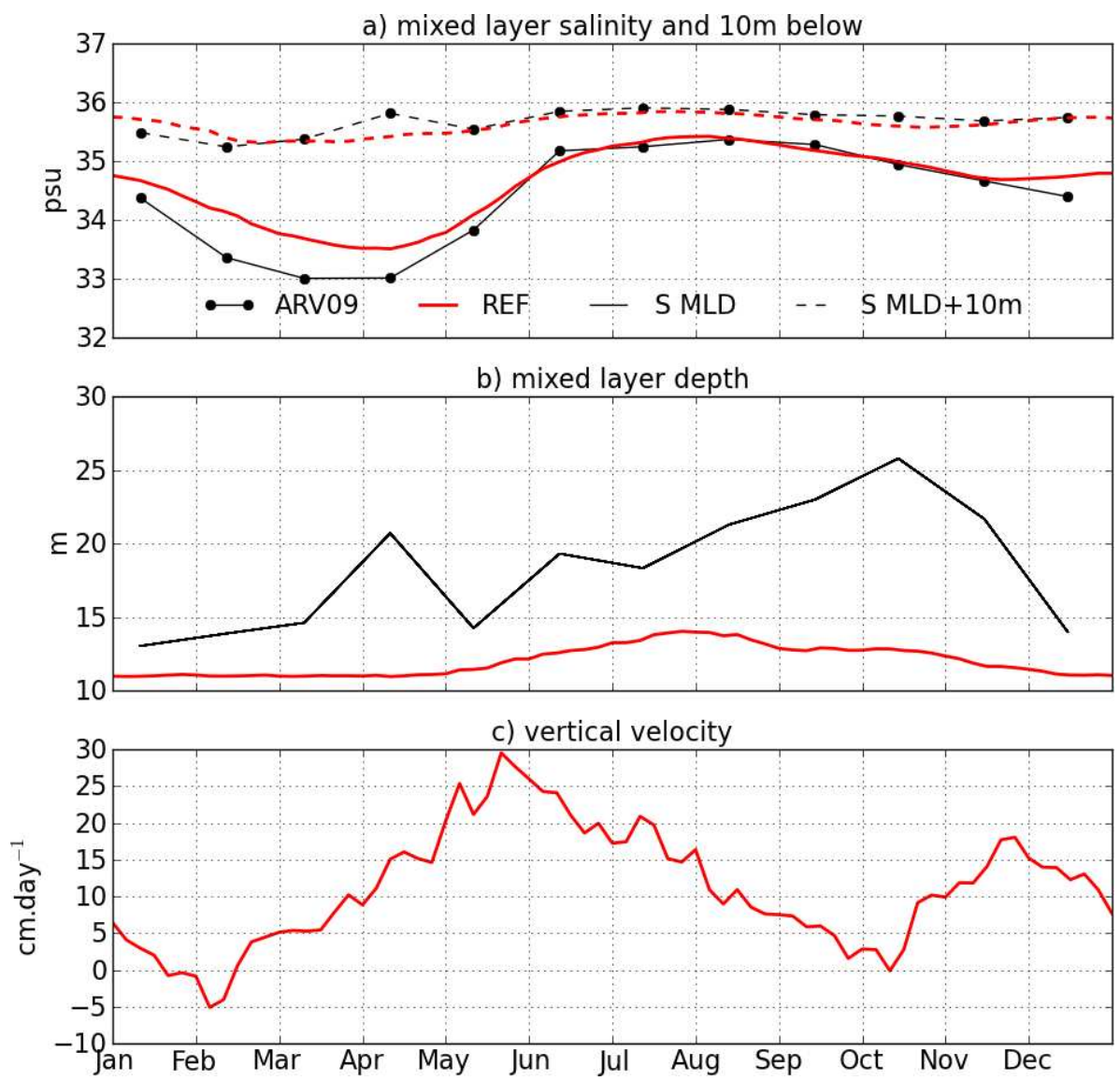

Fig. 12 Mean seasonal values of various fields computed from 1995 to 2006 in the Congo box of Figure 1. a) Mean annual salinity in the mixed layer (continuous) and 10 meters below (dashed) in REF (red) and ARV09 (black). b) Mean annual evolution of the mixed layer depth in REF (red) and the climatology of de Boyer Montegut et al (2004) (black). c) Mean annual vertical velocity in the REF experiment. 

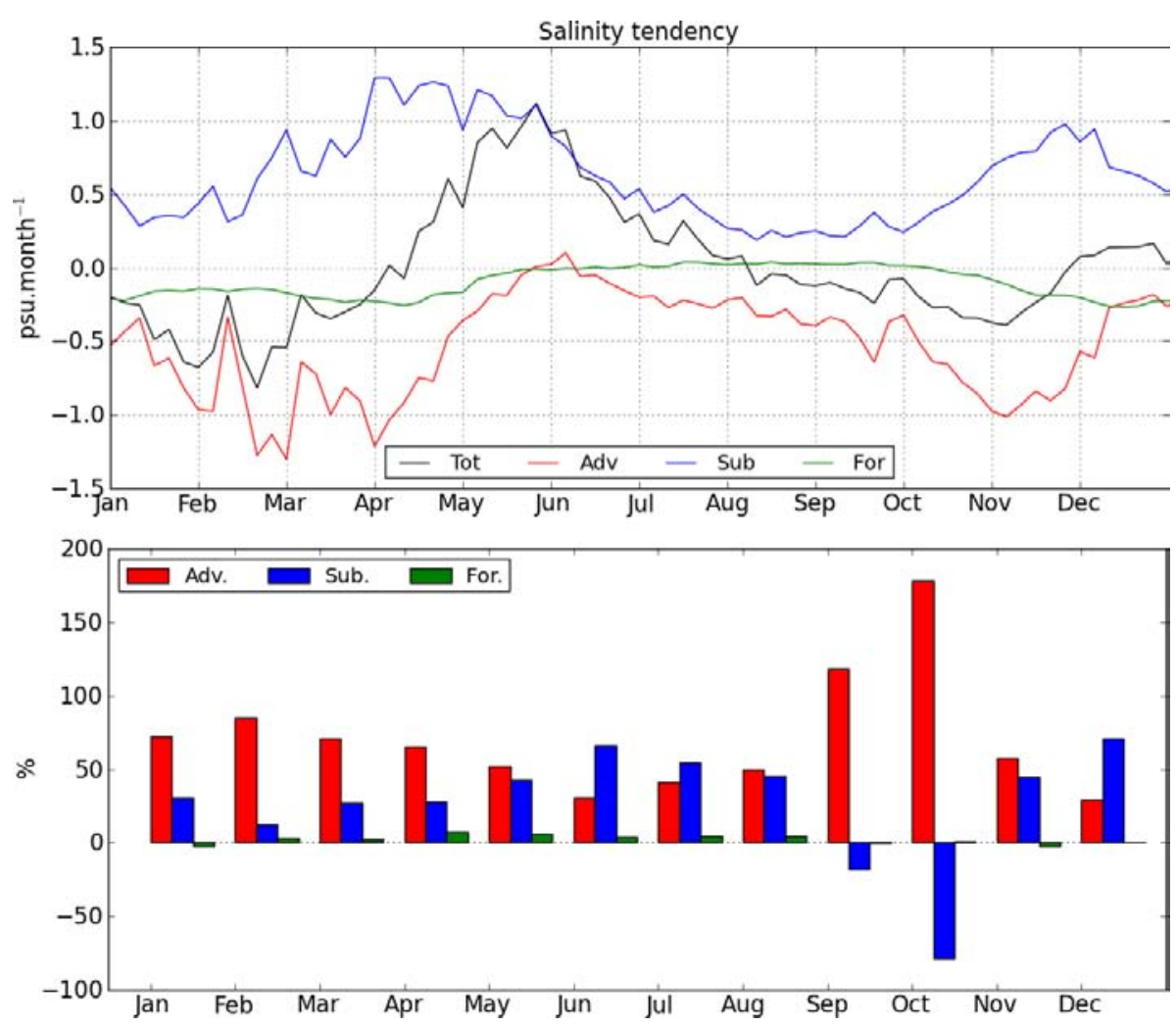

Fig. 13 Top : mean seasonal contributions to the mixed layer budget for salinity of the A, B and $\mathrm{C}$ terms of Equation 1. These contributions have been computed from 1995 to 2006 in the Congo box of Figure 1. Bottom : monthly regression coefficients of the terms of Equation 1 computed using the Equation 3. On these figures, the total trend appears in black, the advection in red, the subsurface processes in blue and the forcing in green. 

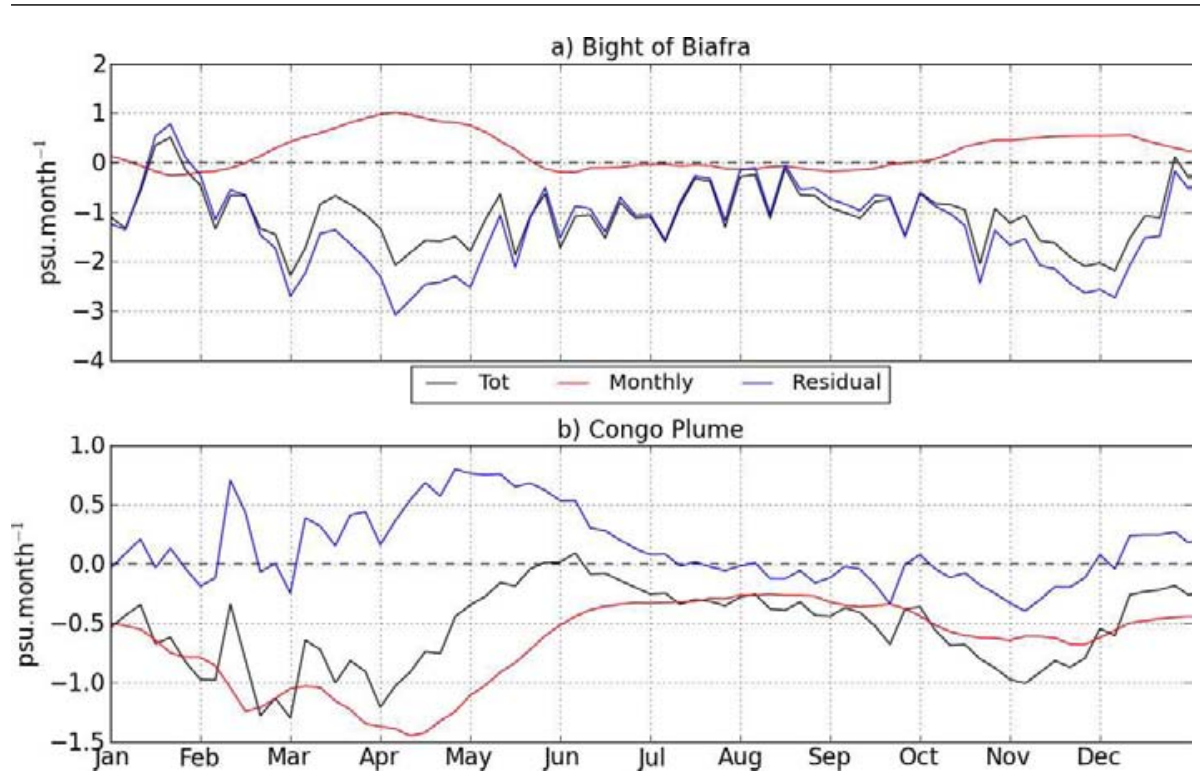

Fig. 14 Decomposition of the horizontal advective term of Equation 1 (in black) into a contribution from the monthly mean seasonal cycle (red) and a residual due to other variabilities such as eddies and high frequency waves (blue) (see Equation 4). 